\title{
A Visão de Desenvolvimento e Mudança Social de Freire: Experiências do Passado, Desafios do Presente e Perspectivas para o Futuro ${ }^{1}$ \\ Freire's Vision of Development and Social Change: Past Experiences, Present Challenges, and Perspectives for the Future
}

\author{
ANA CRISTINA SUZINA a \\ Loughborough University London, Institute for Media and Creative Industries. Londres, Reino Unido \\ THOMAS TUFTE \\ Loughborough University London, Institute for Media and Creative Industries. Londres, Reino Unido \\ University of the Free State, Department of Communication Science. Bloemfontein - Free State, África do Sul
}

\section{RESUMO}

Este artigo propõe tomar o pensamento de Freire como um modelo ou mesmo paradigma de comunicação, desenvolvimento e mudança social. Para tanto, primeiro delineamos a dimensão ontológica de Freire, apresentando e discutindo seus cinco princípios subjacentes. Em seguida, percorremos seu legado, apresentando e discutindo como ele inspirou três importantes pensadores ibero-americanos, Augusto Boal, Juan Díaz Bordenave e Boaventura de Sousa Santos. Finalmente, aprofundamos nossa análise da visão de Freire sobre desenvolvimento e mudança social, destacando como ele navega entre uma visão normativa fundamentada em uma aspiração utópica de mudança e uma metodologia muito sistemática e rigorosa, sua pedagogia libertadora.

Palavras-chave: Desenvolvimento, mudança social, comunicação, Paulo Freire, epistemologias do Sul

\section{ABSTRACT}

This article proposes to view Freire's thinking as a model or even paradigm of communication, development, and social change. To build this as an original argument, we firstly outline Freire's ontological call, presenting and discussing his underlying five principles. Secondly, we trace Freire's legacy by presenting and discussing how Freire inspired three significant Ibero-American thinkers, Augusto Boal, Juan Díaz Bordenave, and Boaventura de Sousa Santos. Finally, we deepen our analysis of Freire's vision of communication, development, and social change, unpacking how he navigates between a normative vision grounded in a utopian aspiration for change, and a very systematic and rigorous methodology, his liberating pedagogy.

Keywords: Development, social change, communication, Paulo Freire, epistemologies of the South
${ }^{1}$ Artigo originalmente publicado em 2020, no número especial "The Legacy of

Paulo Freire. Contemporary Reflections on Participatory Communication and Civil Society Development in Brazil and Beyond", (Editores convidados: Ana Cristina Suzina, Thomas Tufte e César Jiménez-Martínez) da International Communication Gazette, 82(5), 411-424. https://doi.rg/10.1177/ 1748048520943692

a Professora e pesquisadora do Institute for Media and Creative Industries da Loughborough University London. Editora do livro The Evolution of Popular Communication in Latin America (Palgrave, 2021). Orcid: https://orcid.org/00000003-3559-6513. E-mail: a.suzina@lboro.ac.uk

${ }^{\mathrm{b}}$ Diretor do Institute for Media and Creative Industries da Loughborough University London e professor extraordinário da University of The Free State, África do Sul. É membro da Academia Europaea. Orcid: https://orcid. org/0000-0003-3253-8481. E-mail: t.tufte@lboro.ac.uk 
Se alguém, ao ler este texto, me perguntar, com irônico sorriso, se acho que, para mudar o Brasil, basta que nos entreguemos ao cansaço de constantemente afirmar que mudar é possível e que os seres humanos não são puros espectadores, mas atores também da história, direi que não. Mas direi também que mudar implica saber que fazê-lo é possível. ...

O que não é, porém, possível é sequer pensar em trans-formar o mundo sem sonho, sem utopia ou sem projeto.

-Paulo Freire, Pedagogia da Indignação

\section{INTRODUÇÃO}

TO FINAL DE 2019, o mundo experimentou uma forte onda de mobi$\mathrm{N}$ lização social que trouxe de volta imagens e memórias das mobilizações globais ocorridas em 2010-2011 com as Primaveras Árabes, em países como Tunísia, Egito e Síria, os movimentos dos Indignados, na Grécia e na Espanha, Occupy, nos EUA, que se espalhou globalmente, e outras revoltas no Brasil e na Turquia, em 2013, na África do Sul e no Quênia, em 2015, e em vários outros países. Em 2019, vimos novamente grandes protestos e revoltas, por exemplo, no Líbano, em Hong Kong, no Irã, na França e em vários países latino-americanos como Equador, Haiti, Uruguai e, em particular, uma grande onda de mobilizações no Chile, a maior desde que o país recuperou a democracia, no final da década de 1980. Em meio a isso, o Brasil vivenciou o primeiro ano do recém-eleito governo Jair Bolsonaro, com severa repressão às universidades, à sociedade civil, às comunidades LGBT+, a grupos indígenas e muitos outros. No Brasil, a resistência e a contestação à política dominante emergiram de forma mais fragmentada do que nos outros exemplos dados aqui.

Embora as motivações por trás dessas revoltas obviamente variem, argumentamos que elas têm em comum uma crítica ao desenvolvimento. Recorrentemente, esses movimentos têm contestado e resistido a uma ordem social - e inerentemente a um modelo de desenvolvimento - que não conseguiu combater a pobreza, os níveis alarmantes de desigualdade socioeconômica e as práticas antiéticas de corrupção. As revoltas, embora muitas vezes desencadeadas por ações políticas bastante pontuais - seja um aumento nas tarifas de transporte, a proibição do WhatsApp, uma lei injusta ou um corte no setor saúde - tendiam a expressar fortes sentimentos de exclusão, de impossibilidade de sobreviver na vida cotidiana e de descaso pelos políticos. Tais experiências de falta de participação, de desigualdade social e de silenciamento compõem uma assimetria 
de poder (Suzina, 2016, 2018) e, mais concretamente, uma negação dos valores e princípios que estão no centro da visão de desenvolvimento de Paulo Freire.

Neste artigo, argumentamos que o pensamento de Freire constitui não apenas uma visão pedagógica, mas uma visão maior e mais profunda da comunicação e do desenvolvimento, baseada em um conjunto de princípios e valores fundamentais que norteiam a constituição de uma ordem social, inspiram uma prática de comunicação e interação social, e servem como guia normativo para a convivência em sociedade. Sugerimos que o atual governo brasileiro considera Paulo Freire um homem perigoso e se esforça para banir suas ideias em todo o país porque as ideias de Freire constituem uma visão de desenvolvimento fundamentalmente oposta às dele.

Assim, o modelo de comunicação decorrente de uma perspectiva freiriana é completamente diferente daquele mobilizado pelo governo Bolsonaro. Silvio Waisbord (2020) argumenta que "a obsessão com o legado de Freire reflete a oposição agressiva do populismo de Bolsonaro aos princípios centrais da esfera pública democrática. Freire apresentou uma visão de comunicação pública que é antitética à visão populista” (p. 449). Em outro trabalho, Suzina (2020) definiu a apropriação da comunicação por movimentos conservadores e de direita sob a noção de "dissonância restritiva", principalmente por ser orientada para a aniquilação de toda e qualquer voz ou perspectiva diferente ou contraditória.

Este artigo está dividido em três seções. Na primeira, descrevemos a dimensão ontológica de Freire e seus princípios subjacentes, recorrentes na maior parte de seu pensamento. Na segunda, discorremos sobre o legado de Freire, apresentando e discutindo como ele inspirou Augusto Boal, Juan Díaz Bordenave e Boaventura de Sousa Santos. A pesquisa e a prática desses três importantes pensadores ibero-americanos mobilizam o legado de Freire em desdobramentos globais no teatro, na comunicação participativa e no domínio da epistemologia. Finalmente, aprofundamos nossa análise da visão de Freire sobre a comunicação, o desenvolvimento e a mudança social, destacando como ele navega entre uma visão claramente normativa, alicerçada em uma aspiração utópica, de um lado, e uma metodologia muito sistemática e rigorosa, sua pedagogia libertadora, de outro.

\section{A DIMENSÃO ONTOLÓGICA DE FREIRE}

Para compreender a atualidade de Paulo Freire, é preciso reconhecer uma distinção entre situar seu trabalho no passado, no presente, ou considerar sua relevância nas discussões sobre futuros caminhos de desenvolvimento. As ideias de Freire evoluíram historicamente, do final da década de 1940 até o final dos anos 1990. Suas contribuições seminais são das décadas de 1960 e 1970, uma época de 
autoritarismo, altos níveis de analfabetismo e desigualdades socioeconômicas, especialmente no interior rural do Nordeste, onde começou sua experiência. Cicilia Peruzzo (2020) traça essas origens, propondo alguns pilares fundamentais para compreender o pensamento de Freire em geral e, mais particularmente, como ele se refere à comunicação e à mudança social. Seu trabalho permanece relevante porque se aplica a todas as situações em que uma sociedade é confrontada com uma disputa sobre seu modelo de desenvolvimento, ou seja, o modo como quer proteger, produzir e compartilhar riqueza e como seus membros participam desse processo. Waisbord (2020) situa o atual governo populista de direita, fortemente influenciado por grupos religiosos conservadores, dentro da onda mais ampla de movimentos conservadores na América Latina. Assim, ele dá uma noção do que está atualmente em jogo no Brasil e de como a filosofia de Freire pode informar um debate que transcende fronteiras.

A dimensão ontológica de Freire está associada a cinco princípios, humildade, empatia, amor, esperança e diálogo (Freire, 1968/2017, p. 33), que ele apresentou como o espírito de uma de suas principais obras de referência, Pedagogia do Oprimido, publicada originalmente em 1968. Como ele também reconhece, é uma ontologia que tende a dividir as pessoas, porque pode ser vista como muito idealista por alguns, enquanto é rejeitada por outros que não se alinham com seu tom crítico e de denúncia contra os opressores.

Fortemente enraizada em uma análise marxista da sociedade, a visão de Freire coloca pessoas reais, bem como instituições, em um contexto de relações de poder, negando a possibilidade de um posicionamento neutro. Desse modo, ele assume uma posição normativa clara. Mas essa posição também é uma visão contextual e dinâmica, que aponta para janelas de oportunidade, esperança e transformação, todas vistas como processos que podem mudar ambos os lados. A humanização, como definida por Freire, não consiste apenas em reposicionar os oprimidos em melhores condições. Trata-se de redesenhar completamente a relação oprimido-opressor e atacar a assimetria de poder a partir da dimensão ontológica freiriana e seus princípios subjacentes, que desenvolvemos a seguir.

O diálogo é o mecanismo central de mudança para Freire e é isso que faz Peruzzo (2020) definir que, mais do que pedagógica, a visão de Freire é de comunicação. Como ela afirma, a comunicação está profundamente inscrita em seu modelo de ensino e aprendizagem, é parte integrante de um intercâmbio permanente entre professores e alunos. Waisbord (2020) leva o argumento um passo adiante, sugerindo que "comunicação é como aprendemos a ser humanos" e destacando como a obra de Freire exibe vários recursos que configuram um "projeto de comunicação democrática" que se choca com qualquer manifestação de populismo. O diálogo é, portanto, um princípio transversal. 
Freire coloca a humildade como um requisito fundamental para reconhecer que as pessoas - todas as pessoas - têm conhecimento. O diálogo, alcançado por meio da comunicação e com humildade, torna-se um local de encontro na vida cotidiana, na qual o conhecimento é construído e reconstruído permanentemente. Esse é um princípio que ajuda a analisar o surgimento de vozes de direita no Brasil, assunto que é densamente e provocativamente analisado tanto por Helton Levy (2020) quanto por Fanny Vrydagh e César Jiménez-Martínez $(2020)^{2}$. Como os casos estudados por esses autores revelam, existe uma evidente disputa para articular um processo pelo qual a verdade se cristaliza vinculada um grupo. No entanto, a humildade sugere que a verdade autêntica não pertence a nenhum indivíduo ou grupo, nem é imposta por um grupo a outro. A verdade autêntica - ou a palavra autêntica, na terminologia de Freire - é, sim, o resultado de um exercício permanente de ação e reflexão que leva em conta a realidade e a perspectiva de cada participante em qualquer relação (Suzina, 2020).

A empatia vai além da generosidade. Na visão de desenvolvimento de Freire, não há espaço para a caridade no sentido de classificar pessoas vulnerabilizadas como carentes ou deficientes em qualquer sentido. Em vez disso, o princípio da empatia é uma forma de reconhecer diferentes pontos de partida que dificultam que alguns alcancem seus objetivos. O princípio da empatia reconhece as desigualdades e as toma como questões coletivas, em vez de uma questão de esforço ou mérito individual. A necessidade, ou estar em necessidade, é um sinal de dominação de alguns sobre outros. Assim, a empatia é necessária para desencadear uma mudança que fornecerá aos dominados o que é necessário para romper o ciclo de opressão.

O princípio do amor leva a uma abordagem que conecta a razão com os sentidos. Raquel Paiva (2020) enfatiza a natureza cultural da pedagogia de Freire, pela qual ele valoriza as relações acima do rigor da disciplina. É um método que reconhece o Outro na plenitude e em todas as formas de conhecimento. No geral, é um modelo de desenvolvimento baseado em laços coletivos, incluindo todos os seres, humanos ou não.

Finalmente, o princípio da esperança significa confiar em uma nova ordem social justa como horizonte a seguir, como na visão de Eduardo Galeano (2012) de utopia, na qual cada passo em direção a ela faz que ela se mova a um passo de distância, sob o objetivo supremo de continuar caminhando.

A esperança é tanto o princípio quanto a regra pela qual se atinge uma visão crítica e uma busca permanente por mudanças: "O trabalho de Freire representa a política comunicativa da esperança - a noção de que os seres humanos podem mudar a si mesmos e transformar condições sociais para produzir uma sociedade mais justa" (Waisbord, 2020, p. 451). Assim, argumenta Waisbord, uma abordagem
${ }^{2} \mathrm{O}$ artigo de Vrydagh e Jiménez-Martínez foi também traduzido e incluído nesta edição especial de MATRIZes. 
freiriana torna-se uma fonte de resiliência democrática. Consequentemente, $\mathrm{o}$ oposto da assimetria não é a simetria, mas é a justiça e a convivência no sentido de produzir um espaço para diferentes formas de ser e compreender.

Esses princípios foram desenvolvidos por Freire em diferentes graus e formas, em todas as suas obras, mas também serviram de inspiração para muitos pensadores e cidadãos em todo o mundo. Na próxima seção, exploramos essa disseminação e nos concentramos em sua influência sobre o trabalho de três autores ibero-americanos.

\section{ACOMPANHANDO A VISÃO DE DESENVOLVIMENTO DE FREIRE NA AMÉRICA LATINA E FORA DELA}

A pedagogia libertadora de Freire foi desenvolvida e refinada ao longo dos cinquenta anos de sua carreira, desde seu primeiro trabalho, em 1947, até sua morte, em 1997. Embora bastante visionário e filosófico, seu pensamento foi fundamentado na experiência prática e em uma metodologia pedagógica rigorosa. Isso torna seu pensamento não apenas inspirador para muitos, mas também acessível e aplicável. Muitos projetos sociais e de desenvolvimento, movimentos sociais, organizações da sociedade civil e comunidades engajadas com questões de justiça e mudança social foram fortemente inspiradas por Paulo Freire.

No campo da comunicação para a mudança social, a influência de Freire foi documentada na extensa coleção editada por Gumucio-Dagron e Tufte (2006): Communication for Social Change Anthology: Historical and Contemporary Readings. De 2004 a 2006, eles fizeram um levantamento global para identificar textos seminais nos cinquenta anos de história do campo da comunicação para a mudança social. Após um amplo processo consultivo global e um processo editorial bastante participativo, envolvendo dez especialistas mundiais, duzentos textos (de citações e fragmentos a artigos completos) foram identificados como seminais para o campo. Desses, $40 \%$ eram da América Latina, e a maioria tinha referências diretas a Freire. Alguns textos da Ásia, África e EUA também fizeram referência explícita a ele. Era evidente a influência global de seu pensamento.

Em retrospecto, está bem documentado como Freire serviu como fonte, como base epistemológica não só no campo da educação, mas para uma ampla gama de pensadores e ativistas engajados no desenvolvimento e mudança social. Na sequência, exploramos três linhas de reflexão e ação significativas que, cada uma a sua maneira, se inspiraram na visão de desenvolvimento e mudança social de Freire. Todas constituem correntes acadêmicas significativas, legítimas e valiosas em si mesmas, mas com o legado do pensamento de Freire embutido solidamente nelas. Revelam a flexibilidade da filosofia de Freire, mas ao mesmo 
tempo um fundamento normativo que vincula suas abordagens a uma espécie de mudança social que desafia o paradigma dominante atual do desenvolvimento.

A primeira linha explora a influência de Freire sobre o teatro para o desenvolvimento, com o Teatro Fórum de Augusto Boal como expoente. A segunda refere-se à influência de Freire na comunicação participativa e na comunicação para a mudança social, ilustrada pelos escritos de Juan Díaz Bordenave. Finalmente, e possivelmente mais significativamente, Freire influenciou o pensamento e a articulação das epistemologias do Sul de Boaventura de Sousa Santos. Esse conjunto delineia linhas significativas para os debates atuais sobre o desenvolvimento e, em particular, sobre a filosofia da ciência que informa debates, conceitos e teorias de comunicação e desenvolvimento.

\section{Encenar a opressão: Augusto Boal e as conexões entre artes e participação}

O Teatro do Oprimido constitui uma abordagem da dramaturgia desenvolvida por outro brasileiro, Augusto Boal, e é profundamente inspirado na obra de Paulo Freire. Consiste em formulações teóricas e práticas fundamentadas em uma experiência concreta. Essa abordagem teatral visa deslocar a experiência daquele que só assiste, o espectador, a fim de transformá-lo em um espect-ator (Boal, 1979), ou seja, alguém capaz de propor mudanças na situação de opressão expressa em cada cena. Dentro dessa dinâmica, o personagem pensa e atua no lugar do espectador, pois interrompe a ação para formular, através da representação, sua capacidade de agir e sua compreensão do que está acontecendo.

De um lado, o Teatro do Oprimido situa-se em um movimento de desenvolvimento da arte participativa, quebrando o silêncio do público para que o teatro deixe de ser o lugar em que alguns encenam (os atores) e outros observam (espectadores), totalmente separados ou com participação limitada no papel uns dos outros (Carpentier, 2011, Cap. 1). De outro lado, pode ser visto como uma abordagem de entretenimento-educação, na qual o processo de conscientização do público está incorporado em uma grande variedade de propósitos de empoderamento (Obregon \& Tufte, 2014). Nesse caso, o espectador é o principal instrumento para a ideia de um teatro que busca quebrar a barreira entre o palco e o público, levando este último para participar de todo o processo de resolução e, também, na distribuição de responsabilidades, engajando, assim, todos no processo de transformação. Esse método envolve pessoas dispostas a refletir, propor e dar sua opinião sobre o exemplo de opressão representado na peça teatral.

Boal articula muitos dos princípios de Freire e reforça particularmente aquele relacionado à conscientização e também seu princípio de quebrar o 
silêncio por meio da voz dos oprimidos. Ele é apropriado por associações globais e locais no campo do desenvolvimento, comprovando seu caráter prático na identificação de problemas comuns e na construção de soluções coletivas. Um bom exemplo disso tem sido o uso do Teatro do Oprimido, o Teatro Fórum em particular, durante décadas na luta contra o HIV/AIDS na África Subsaariana (Tufte, 2015, Cap. 3-5).

Como uma abordagem para a mudança social, relaciona-se à perspectiva de Freire de que ninguém deveria prever o futuro em nome de nenhum indivíduo ou comunidade, sendo a plena participação das pessoas a única forma de uma esfera pública democrática, como argumenta Waisbord (2020). Esse futuro pode, por exemplo, não ser a reprodução de regras conservadoras que os atores de direita buscam como forma de estabilizar a sociedade, nem a linha reta para um futuro ideal projetado pela esquerda. O futuro é uma obra aberta. A autonomia dos espect-atores na direção das cenas é uma prefiguração da autonomia que Freire postula como necessária para uma permanente redefinição do futuro, com base em um constante processo de ação e reflexão.

A sociedade participativa: Juan Díaz Bordenave e o "arco da participação"

O paraguaio Juan Díaz Bordenave é provavelmente um dos autores que levou a ideia freiriana de participação mais adiante. Em seu doutorado, estudou comunidades rurais de Pernambuco, no Brasil (Orué Pozzo, 2014), na mesma região onde Freire desenvolveu e colocou em prática seu método pedagógico, alfabetizando centenas de adultos camponeses. Juntamente com sua experiência em desenvolvimento rural e seu forte interesse pela Teologia da Libertação, sua pesquisa de campo influenciou Bordenave na definição de princípios que poderiam impulsionar o que ele chamou de sociedade participativa (Bordenave, 1989).

Em nível pessoal, Bordenave foi quem Freire primeiro procurou em 1964, após o golpe militar no Brasil, quando precisou se exilar. O paraguaio era, então, o diretor de comunicações do Instituto Interamericano de Cooperação para a Agricultura (IICA), no Peru. No entanto, antes de Bordenave responder ao pedido de ajuda, Freire se exilou na Embaixada boliviana no Brasil, indo pouco depois para a Bolívia, e em seguida para o Chile, onde permaneceu por mais de quatro anos. Somente muitos anos depois, no final da década de 1970, seus caminhos se cruzaram novamente, quando Bordenave restabeleceu contato, aproximando-se de Freire enquanto ele ainda estava no exílio, em Genebra, onde atuava no Conselho Mundial de Igrejas (Tufte, 2013, pp. 12-13).

Geralmente, entendemos a participação a partir de dois caminhos teóricos. O primeiro decorre das ciências sociais e destaca qualquer processo ou prática 
que integre diferentes atores na realização de algo. Trata-se de participar - ou permitir que outros participem - de um projeto ou atividade. O segundo caminho vem da ciência política e discute como equalizar o poder. Ainda se trata de fazer coisas juntos, mas vai além disso para analisar como as pessoas se reúnem e tomam parte nas decisões sobre a forma como trabalham e o destino que perseguem. Essa diferença é explorada em abordagens que definem níveis ou graus de participação, como na "escada de participação cidadã" desenvolvida por Sherry Arnstein (1969), ou outras que distinguem a interação da participação, como a proposta por Nico Carpentier (2012). Essas duas perspectivas estão entrelaçadas na obra de Freire e claramente explícitas na obra de Bordenave, para quem a participação é um direito humano que possibilita o surgimento da subjetividade individual, bem como a legitimidade dos membros ativos de uma comunidade, o que significa a capacidade de interferir na definição do destino coletivo (Bordenave, 1989, p. 19). O movimento em direção a uma sociedade participativa implica uma profunda mudança nas relações desde o nível familiar até o do Estado.

Como profissional e intelectual, Bordenave influenciou fortemente o campo da comunicação para o desenvolvimento, usando suas reflexões sobre a participação para superar os métodos intervencionistas. Uma inspiração central foi o livro Extension o Comunicacion? La Concientizacion en el Medio Rural (Freire, 1973). Nessa pequena, mas significativa obra, Freire constrói uma dura crítica à forma como a comunicação é concebida no setor agrícola. Ainda hoje existe a noção de trabalhador extensionista. Freire via isso como um conceito muito linear, não participativo, promovendo o que ele chamou de "invasão cultural". Ele propôs uma nova maneira integral, alinhada com suas ideias da Pedagogia do Oprimido, de conceituar esses agentes de mudança que atuam no setor agrícola. Para Bordenave, o livro de Freire foi crucial, um ponto de virada. O paraguaio foi formado intelectualmente por alguns dos principais acadêmicos dentro do paradigma da difusão da inovação, em particular, Everett Rogers. Assim como outros importantes estudiosos latino-americanos inspirados por Freire, como Orlando Fals-Borda e Luis Ramiro Beltrán, Bordenave recebeu uma bolsa de estudos para estudar nos EUA na década de 1950. Assim, embora a formação intelectual de origem desses autores estivesse inserida em um paradigma linear, funcionalista de comunicação e desenvolvimento, seus conhecimentos posteriores com Freire os levaram a revisar seus posicionamentos. 
Todas as pessoas têm conhecimento: $\mathrm{O}$ desafio epistemológico de Boaventura de Sousa Santos

O professor de sociologia português Boaventura de Sousa Santos desenvolveu, ao longo dos anos, um ambicioso projeto para formular uma epistemologia do Sul. Este projeto de ciências sociais critica o discurso dominante na ciência moderna, sugerindo caminhos epistemológicos alternativos e defendendo uma ruptura epistemológica. As ideias de Santos estão enraizadas na reivindicação fundamental de justiça cognitiva global que, em termos freirianos, explora a esperança de um futuro melhor por meio de um esforço integrado que combine reflexão e ação.

Enquanto o livro de Sousa Santos (2014) The Epistemologies of the South: Justice Against Epistemicide constituiu uma proposta impactante para esse caminho alternativo, é em sua obra mais recente, The End of the Cognitive Empire (2018), que ele analisa como abordar e desafiar as instituições em que o conhecimento científico eurocêntrico é produzido. Ele argumenta que abordar essa dominância global de um império cognitivo específico desafia tanto a pesquisa, o tipo de conhecimento produzido, mas igualmente as pedagogias que fazem parte do desenvolvimento de ecologias específicas do conhecimento. É nesse contexto que ele desvenda como tanto o pai colombiano da pesquisa de ação participativa, Orlando Fals-Borda, quanto a pedagogia libertadora de Paulo Freire influenciaram seu conceito de epistemologias do Sul.

Para Boaventura, práticas extra-institucionais, como a luta social, muitas vezes são centrais para o desenvolvimento das epistemologias do Sul. Elas:

apontam para práticas de crítica e possibilidade, inconformidade e resistência, denúncia e contraproposta. ... Institucionalidades e pedagogias prefigurativas são modos de organizar o convívio coletivo e promover processos de aprendizagem libertadores, capazes de realizar, aqui e agora, e em pequena escala, outro futuro possível. (Sousa Santos, 2018, pp. 248-249)

É nesse contexto que ele reconhece a forte influência de Freire: "as epistemologias do Sul não teriam sido possíveis sem duas grandes propostas que revolucionaram a pedagogia e as ciências sociais no final da década de $1960 \mathrm{e}$ durante a década de 1970" (Sousa Santos, 2018, p. 253). Boaventura fala sobre uma "razão quente", aquela que lida com emoções e afetos sem perder a inteligibilidade. Freire define a "palavra verdadeira" como algo que funciona tanto como uma forma de trabalhar, implicando tomar todos como iguais, capazes de conhecer, e como uma projeção para o futuro, em que as palavras não apenas descrevem fatos, mas projetam uma utopia. A ecologia do conhecimento 
diz respeito ao reconhecimento de diferentes saberes e à restituição do poder a todas as pessoas, representando o mundo como pertencente a elas e em seus próprios termos.

Tal abordagem é central para diversas iniciativas de desenvolvimento de baixo-pra-cima em que Sousa Santos esteve envolvido. Foi um princípio norteador na experiência brasileira com o orçamento participativo, processo iniciado em Porto Alegre, em 1989, como um projeto com aspirações para alcançar a democracia participativa. Essa iniciativa incentivou e alcançou ampla participação política, principalmente em torno do orçamento público municipal, e desde então se espalhou para centenas de cidades em todo o mundo (Tufte, 2017). Sousa Santos a identificou como o surgimento de uma "cultura tecnodemocrática".

As ideias de Sousa Santos também foram influentes nos Fóruns Mundiais Sociais, especialmente os iniciais, realizados em Porto Alegre na primeira década dos anos 2000. Aqui, seu pensamento, suas críticas ao estado geral das coisas, à consequência social da globalização, em particular, foram importantes. Sua defesa da voz, da participação e da luta social para acabar com a injustiça social e cognitiva ressoaram fortemente entre os muitos movimentos sociais e associações de base comunitária ali engajados. Embora as ideias de Freire estivessem muito presentes e visíveis nas lutas pró-democracia no Brasil nos anos 1970 e especialmente na década de 1980, tornaram-se menos visíveis nas décadas de 1990 e 2000, quando a influência de Sousa Santos cresceu, e ele se estabeleceu como um importante intelectual público no Brasil e em toda a América Latina. O ponto interessante demonstrado aqui é a inspiração intelectual de Sousa Santos, proveniente de Freire.

\section{O GLOBAL AGORA: CRITICANDO O DESENVOLVIMENTO, REIVINDICANDO VOZ, PARTICIPAÇÃO E JUSTIÇA SOCIAL}

O desenvolvimento histórico e a influência de Freire sobre esses três pensadores revelam ligações epistemológicas e ajudam a entender as conexões entre a insatisfação e as consequentes mobilizações que florescem em diferentes partes do mundo. Como mencionamos anteriormente, essas últimas são frequentemente desencadeadas por políticas que, embora pontuais, revelam uma condição maior de desigualdade e um sentimento de assimetria de poder, experimentados por bilhões de pessoas vivendo sob o mesmo modelo injusto de desenvolvimento, que é constantemente justificado por uma engrenagem cognitiva dominante. São os clamores da experiência concreta da injustiça tentando ocupar o palco e reivindicar alternativas. 
O que essas ondas de protesto têm em comum com a "polarização perniciosa" (Vrydagh \& Jiménez-Martínez, 2020) no Brasil que abriu caminho para a eleição de um governo federal de extrema direita? Do ponto de vista freiriano, acreditamos que existem duas chaves analíticas principais que ajudam a responder a essa pergunta. Em primeiro lugar, há o contexto histórico das injustiças sociais e cognitivas. Em segundo, pelo outro lado, está a política da esperança.

Como já evocamos, as experiências de falta de participação, de desigualdade social e de não ter voz constituem um quadro geral de assimetria de poder. Suzina (2018) descreveu o Brasil como uma democracia assimétrica porque, além das desigualdades estruturais e históricas, seus cidadãos dificilmente conseguem intervir na (re)definição da ordem social, ou seja, é uma barreira quase impossível de ser ultrapassada por grupos sociais marginalizados. Levy (2020) oferece um exemplo ilustrativo disso, mostrando uma periferia que se cansou de ser (mantida) silenciosa e, assim, desenvolveu gramáticas de contestação para expressar suas reivindicações e opiniões. Embora vindo de circunstâncias muito diferentes, um sentimento semelhante de falta de voz é descrito por Vrydagh e Jiménez-Martínez (2020), que argumentam que a polarização observada no Brasil foi sustentada por percepções, mais do que por diferenças irreconciliáveis. Ambos os estudos analisam o surgimento de vozes de direita no país e, de diferentes formas, contribuem para confirmar os traços gerais das assimetrias.

Levy (2020) traz à tona o caso de pessoas que realmente vivem sob o domínio das injustiças ou abandonadas pelo poder público, tratadas com paternalismo ou culpabilizadas por suas supostas falhas e, portanto, merecedoras de um destino miserável. Vrydagh e Jiménez-Martínez (2020) descrevem o que poderia ser chamado de performances de contestação, nas quais há uma apropriação da consciência popular da injustiça convertida na reprodução de repertórios geralmente associados a movimentos progressistas, como marchas populares e ocupação de prédios públicos. A busca por expressão associa-se a um sentimento compartilhado de dominação.

A relevância de olhar para essa questão do ponto de vista da injustiça social e cognitiva é que podemos ver como a prevalência da assimetria de poder é um terreno fértil para o surgimento pretensos líderes. Vrydagh e Jiménez-Martínez (2020) sugerem que regimes autoritários e/ou populistas podem emergir como resultado de uma "polarização perniciosa". Waisbord (2020) situa o governo Bolsonaro como um manual de populismo para, de certa forma, institucionalizar essa assimetria sob a dicotomia de amigos e inimigos. Assim, também podemos ver como uma falsa ideia de libertação pode emergir nesse contexto.

Para Freire, não há libertação real sem um processo coletivo, contextual e histórico. Na Pedagogia do Oprimido (1968/2017), ele argumenta que não há 
liberação se esta não integra um processo mútuo. Se os oprimidos e opressores apenas trocam de posição, nenhuma transformação sustentável foi alcançada. Apesar de se autoproclamar portadora da verdade, a direita que chegou ao poder no Brasil está longe da palavra verdadeira, conforme a definição de Freire.

Como Suzina (2020) discutiu anteriormente sob o conceito de dissonância, tecnicamente, a apropriação da palavra, nesses termos, envolve ação e reflexão, como conceitualizado por Freire. No processo de mudança social, é uma palavra que busca e causa dissonância. A distinção refere-se ao que ela aponta como o horizonte. A palavra autêntica orienta o surgimento de vozes em direção à convivência e à justiça cognitiva, enquanto a palavra inautêntica desrespeita um pilar central da pedagogia de Freire, que é a eliminação de qualquer forma de dominação. A verdadeira libertação por meio da apropriação da palavra não busca substituir aqueles no poder, mas romper o ciclo de dominação e criar uma nova ordem, na qual opressores e oprimidos se tornam iguais.

Paulo Freire se esforçou para trabalhar com essas ideias. Inspirou e conseguiu articular esses processos de libertação por meio de sua contínua experiência biográfica de trabalho com a pedagogia libertadora. Ele fez isso no Brasil nas décadas de 1940 e 1950, culminando em seu trabalho com a campanha nacional de alfabetização para o Ministério da Educação, pouco antes do golpe militar de 1964. No exílio entre 1964 e 1979, escreveu algumas de suas obras seminais enquanto estava no Chile, esteve algum tempo em Harvard na década de 1970, e foi contratado pelo Conselho de Igrejas, em Genebra, para aplicar suas ideias em trabalhos de alfabetização em países como Angola, Guiné-Bissau e Nicarágua. De volta ao Brasil, na década de 1980, a ditadura militar estava afrouxando seu controle, a sociedade civil estava crescendo e movimentos sociais se fortalecendo. Freire tornou-se professor universitário, mais tarde foi político, por um breve período, mas se manteve principalmente uma inspiração fundamental para a sociedade civil brasileira.

\section{CONSIDERAÇÕES FINAIS}

Em 1987, quando o ramo urbano do Movimento dos Trabalhadores Rurais Sem-Terra realizou suas primeiras ocupações na Zona Leste de São Paulo, um de nós teve a oportunidade de vivenciar as ocupações e entrevistar Paulo Freire em sua casa, em São Paulo. Ao refletir sobre o que estava acontecendo, Freire foi resoluto em abordar o conflito sob a perspectiva do poder. Para ele, o movimento sem-terra, fundamentado nos princípios de humildade, empatia, amor e esperança, foi gradativamente conquistando o espaço, não apenas no sentido material da palavra, mas em termos discursivos, conquistando a palavra por 
meio do diálogo. No entanto, ele foi claro ao dizer que aquele era um processo, um desafio, que exigia ação, mas também reflexão, ou pensamento estratégico (Freire, comunicação pessoal, 11 de junho, 1987).

Falou sobre ser pacientemente impaciente - ver também a descrição de sua esposa, A. Freire (2004, p. xxix) - e refletiu claramente o rigor de sua própria pedagogia original, o método Paulo Freire, desenvolvido e apresentado pela primeira vez na Pedagogia do Oprimido (1968/2017), mas refinado em Extensão ou Comunicação? (1973), em Pedagogia da Esperança (1992/2009) e em Pedagogia da Liberdade, publicado em 1998, um ano após sua morte. Nesse último livro, ele resgata com ênfase a dimensão utópica de sua obra, uma dimensão que é altamente orientada para a ação no sentido de que a educação é "aquele ato especificamente humano de intervir no mundo" (Freire, 1998, p. 6), e ainda:

Quando falo em intervenção, me refiro tanto à que aspira por mudanças radicais, na sociedade, em áreas como a economia, as relações humanas, a propriedade, o direito ao trabalho, a terra, a educação, a saúde, quanto à que, pelo contrário, reacionariamente pretende imobilizar a história e preservar uma ordem socioeconômica e cultural injusta. (p. 6)

Ele insistiu em conectar a democracia à base - a democracia radical - e à libertação humana. E, apesar de falar sobre amor e empatia, também insistiu no direito de estar irritado, com raiva da injustiça social em todas as suas formas.

A visão ousada de Freire sobre o desenvolvimento anda de mãos dadas com a visão clara do tipo de mudança social concebida por ele. Há uma normatividade em sua perspectiva de mudança social que está ligada ao objetivo de eliminar as assimetrias e ao método de realizar trabalho de base com ação e reflexão. Não é surpresa, portanto, que muitos comunicadores/as populares inspirados por Freire digam que a boa comunicação não vem da mente, mas dos pés que pisam no barro com os pobres (Suzina, 2018).

A visão de Freire não pode ser entendida de maneira parcial. Está em Boal, em Bordenave, na epistemologia do Sul de Sousa Santos, e é um critério definidor quando se deseja compreender os limites da aplicação de Freire, ao analisar os movimentos e dinâmicas sociais de direita no Brasil contemporâneo. Se um movimento reivindica vozes, isso deve estar baseado na palavra autêntica. Mesmo que seja o caso de aumentar a consciência para se posicionar no mundo, isso ainda é diferente do nível de conscientização de Freire, no qual o posicionamento no mundo não significa trocar de lugar com o opressor, mas pôr fim a qualquer tipo de opressão e tornar as pessoas iguais, humanas. Quando Freire diz que os oprimidos podem humanizar os opressores, ele fala disso. Não 
há fim para a opressão se a dominação apenas mudar de mãos. Freire escrevia constantemente, e muitas vezes no formato de cartas. Assim, a primeira citação nesse artigo, assim como a última são de uma das quatro cartas publicadas anos depois, no livro Pedagogia da Indignação (Freire, 2004), organizado por sua viúva Ana Maria Araújo Freire. Estas cartas foram escritas entre dezembro de 1996 e maio de 1997, os últimos meses de sua vida. A segunda delas foi intitulada "Do Direito e do Dever de Mudar o Mundo", e nela argumentava contra a educação neutra e reafirmava sua visão libertadora sobre a intervenção, também refletindo sobre o crescente Movimento Sem-Terra no Brasil, que associa à rebeldia dos Quilombos, as sociedades comunitárias utópicas estabelecidas por escravos em fuga séculos atrás. Refletindo a respeito do primeiro, mas olhando muito além dele também, Freire reafirma sua visão de desenvolvimento da seguinte forma:

Que bom seria para a ampliação e a consolidação de nossa democracia, sobretudo para sua autenticidade, se outras marchas se seguissem à sua. A marcha dos desempregados, dos injustiçados, dos que protestam contra a impunidade, dos que clamam contra a violência, contra a mentira e o desrespeito à coisa pública. Não esqueçamos também as marchas dos sem-teto, dos sem-escola, dos sem-hospital, dos renegados, e a marcha esperançosa dos que sabem que mudar é possível. (Freire, 2004, p. 40) M

\section{REFERÊNCIAS}

Arnstein, S. R. (1969). A ladder of citizen participation. Journal of the American Institute of Planners, 35(4), 216-224. https://doi. org/10.1080/01944366908977225

Boal, A. (1979). The theatre of the oppressed. Pluto.

Bordenave, J. D. (1989). La sociedad participativa. Chasquí: Revista Latinoamericana de Comunicación, (32), 18-24. https://bit.ly/2V09WjL

Carpentier, N. (2011). Media and participation. A site of ideological-democratic dispute. Intellect.

Carpentier, N. (2012). The concept of participation. If they have access and interact, do they really participate? Fronteiras - Estudos Midiáticos, 14(2), 164-177. https://doi.org/10.4013/fem.2012.142.10

Freire, A. M. A. (2004). Prologue. In P. Feire, Pedagogy of indignation (pp. xxvii-xxxii). Paradigm.

Freire, P. (1973). Extension o comunicacion? La concientizacion en el medio rural. Siglo Veintinuno. 
Freire, P. (1998). Pedagogy of freedom. Ethics, democracy, and civic courage. Roman and Littlefield.

Freire, P. (2004). Pedagogy of indignation [Pedagogia da indignação]. Paradigm. Freire, P. (2009). Pedagogy of hope [Pedagogia da esperança]. Continuum. (Trabalho original publicado em 1992)

Freire, P. (2017). Pedagogia do oprimido (63a ed.). Paz e Terra. (Trabalho original publicado em 1968)

Galeano, E. (2012, 30 de agosto). Para que sirve la utopía? [Entrevista em vídeo]. YouTube. https://bit.ly/37tdFZr

Gumucio-Dagron, A., \& Tufte, T. (Eds.). (2006). Communication for social change anthology: Historical and contemporary readings. Communication for Social Change Consortium.

Levy, H. (2020). Grammars of contestation and pluralism: Paulo Freire's action in Brazil's periphery and the rise of right-wing discourse on YouTube. International Communication Gazette, 82(5), 474-489. https://doi. org/10.1177/1748048520943696

Obregon, R., \& Tufte, T. (2014). Rethinking entertainment-education for development and social change. In: K. Wilkins, T. Tufte \& R. Obregon (Eds.), The handbook of development communication and social change (pp. 168188). Wiley-Blackwell.

Orué Pozzo, A. (2014). Juan Díaz Bordenave, una comunicación para la vida. Revista Internacional de Comunicación y Desarrollo, 1(0), 51-57. https:// bit.ly/3lhDvIg

Paiva, R. (2020). Communities of affect: A Freirean utopia? International Communication Gazette, 82(5), 490-503. https://doi. org/10.1177/1748048520943697

Peruzzo, C. M. (2020). Paulo Freire's role and influence on the praxis of popular communication in Brazil. International Communication Gazette, 82(5), 425-439. https://doi.org/10.1177/1748048520943693

Sousa Santos, B. (2014). Epistemologies of the South: Justice against epistemicide. Paradigm.

Sousa Santos, B. (2018). The end of the cognitive empire. Duke University Press. Suzina, A. C. (2016). Digital resources in popular media practices in Brazil: Strategies to reduce asymmetries in the public debate. Observatorio $\left(O B S^{*}\right)$, (Número especial: Internet and Social Movements in the context of asymmetries), 11-34. https://doi.org/10.15847/obsOBS0020161081

Suzina, A. C. (2018). Popular media and political asymmetries in the Brazilian democracy in times of digital disruption [Tese de doutorado não publicada]. Universite Catholique de Louvain. 
Suzina, A. C. (2020). Discursos dissonantes: Problematizando um modelo de comunicação libertadora através dos conceitos de coexistencia e justiça cognitiva. In N. Prata \& S. C. Pessoa (Orgs.), Fluxos comunicacionais e crise da democracia (pp. 88-101). Intercom. https://bit.ly/3CFG23Z

Tufte, T (2013). Homenagem a Juan Díaz Bordenave. ComSertões. Revista de Comunicação e Cultura no Semiárido, 1(1), 5-17. https://doi.org/10.36943/ comsertoes.v1i1.682

Tufte, T. (2015). Comunicación para el cambio social. La participación y el empoderamiento como base para el desarrollo mundial. Icaria.

Tufte, T. (2017). Communication for social change: A citizen perspective. Polity. Vrydagh, F., \& Jiménez-Martínez, C. (2020). Talking to the right-wing: Pernicious polarization in Brazil and the philosophy of Paulo Freire. The International Communication Gazette, 82(5), 456-473. https://doi. org/10.1177/1748048520943695

Waisbord, S. (2020). Why Paulo Freire is a threat for right-wing populism: Lessons for communincation of hope. The International Communication Gazette, 82(5), 440-455. https://doi.org/10.1177/1748048520943694

Artigo recebido em 28 de junho e aprovado em 29 de junho de 2021. 